\title{
A teoria dos arquivos e a gestão de documentos
}

Ana Márcia Lutterbach Rodrigues

Bacharel em Filosofia pela UFFG, Mestre em Ciência da Informação pela

UFMG, Funcionária do Arquivo Público da Cidade de Belo Horizonte.

anamarciall@hotmail.com

Apresenta os principais conceitos da arquivologia, a fim de discutir como eles podem orientar a elaboração de uma metodologia de gestão dos documentos de arquivo, bem como a identificação dos principais problemas a serem superados para o acesso à informação arquivística.

Palavras-chave: Arquivo, Arquivologia, Gestão de documentos, Informação 


\section{Introduç̃̃o}

A atividade denominada records management, originalmente cunhada em inglês e posteriormente traduzida como gestão de documentos, não surgiu da prática ou teoria dos arquivos, mas por uma necessidade da administração pública. Jardim (1987) esclarece:

[..] as instituições arquivísticas públicas caracterizavam-se pela sua função de órgão estritamente de apoio à pesquisa, comprometidos com a conservação e acesso aos documentos considerados de valor histórico. A tal concepção opunha-se, de forma dicotômica, a de 'documento administrativo', cujos problemas eram considerados da alçada exclusiva dos órgãos da administração pública que os produziam e utilizavam' (p.36).

A partir da segunda metade do século passado, há uma reorientação da profissão dos arquivistas diante do volume documental produzido: entra em pauta, mais especificamente na América do Norte, de onde repercute para os demais países ocidentais, a eliminação de documentos antes de serem recolhidos para guarda permanente. É formulado o conceito de ciclo de vida dos documentos de arquivo.

Em 1956, o norte-americano Schellenberg publica o seu Arquivos modernos - princípios e técnicas no qual dedica toda a Parte II à Administração de arquivos correntes onde se encontram os capítulos: Controle da produção de documentos, Princípios de classificação, Sistemas de registro, Sistema americano de arquivamento e Destinação dos documentos. Com esta publicação abre-se a discussão sobre os arquivos correntes e a sua gestão. Isso não significa que, na prática, os arquivos correntes tenham passado a ser tratados com base nos preceitos da arquivologia. As instituições arquivísticas continuaram a tratar apenas os documentos do arquivo permanente e com o objetivo primeiro de atender à pesquisa acadêmica. Essa tradição promoveria o distanciamento da prática da gestão de documentos arquivísticos da teoria dos arquivos.

No Brasil, em |991, a promulgação da Lei 8. I 59, que dispõe sobre a política nacional de arquivos públicos e privados e estabelece as suas competências, vem reforçar a necessidade de um maior envolvimento do arquivista com as questões relacionadas à gestão dos arquivos correntes, pois ela estabelece que a gestão dos documentos públicos correntes é de competência das instituições arquivísticas.

Nessa perspectiva, pretende-se, aqui, identificar quais são os preceitos da arquivologia e o seu significado nos processos de gestão de documentos arquivísticos e as principais dificuldades para o acesso à informação arquivística.

A arquivologia não é um corpo teórico consolidado. Existem abordagens distintas tanto de um país para outro quanto de uma linha de pensamento para outra. Como as dimensões desse artigo não permitem um aprofundamento da discussão sobre essas tensões, tentar-se-á expor os principais conceitos privilegiando a abordagem jenkinsoniana de Luciana Duranti.

resgate de Jenkinson por Duranti vem opor-se à perspectiva schellenbergiana de que os documentos correntes são distintos dos documentos de guarda permanente (TSCHAN, 2002), o que leva Schellenberg
' Na língua inglesa, apenas os documentos de guarda permanente são chamados de archives, os de uso corrente recebem a denominação de records.

2 o ciclo de vida dos documentos de arquivo é composto por três fases: corrente, intermediária e permanente. A passagem dos documentos de uma fase para outra é determinada por um instrumento denominado Tabela de Temporalidade que estabelece, referendando-se num processo de avaliação dos documentos, os prazos de permanência nas fases corrente e intermediária e a sua destinação final: eliminação ou recolhimento ao arquivo permanente. Há aqueles documentos que só saem do âmbito do seu produtor quando este encerra suas atividades ou quando as altera significativamente. Seriam os documentos que provam a sua existência e definem suas atividades além de outros que contribuem para isso. 
a propor que o valor secundário dos documentos, valor para a pesquisa acadêmica, deverá ser a referência nos processos de eliminação de documentos, por parte dos arquivistas, com vistas ao recolhimento para a guarda permanente.

Jenkinson considera o arquivo de guarda permanente uma continuidade do arquivo corrente, condenando a eliminação de documentos por parte do arquivista, pois esta atividade, segundo este autor, deve ficar a cargo exclusivamente do próprio produtor dos documentos. Jenkinson se orienta pelo valor administrativo e entende que os documentos nunca perdem o valor de informação e prova para o seu criador. $O$ valor secundário dos documentos é acidental, como o próprio Schellenberg enxerga, e portanto ele não deve ser referência para eliminações. Essa percepção conduz Jenkinson à formulação das qualidades dos archives de Imparcialidade e Autenticidade.

Diferentemente de Jenkinson e Duranti, busca-se, aqui, considerar todo e qualquer arquivo, incluindo o produzido por pessoa ou família, e não apenas os administrativos e institucionais. Privilegiar a abordagem de Duranti significa, acima de tudo, compreender o arquivo como evidência dos atos do seu criador, sendo os documentos a prova desses atos, sejam eles de uma entidade coletiva, pública ou privada, sejam de uma pessoa.

Além disso, adota-se a perspectiva de Terry Cook, chamada de póscustodial, que considera o arquivo além da sua materialidade, identificando a proveniência dos documentos mais nas ações que os geraram do que no local onde eles foram produzidos ou de onde foram recolhidos, conforme se pretende que ficará explícito ao longo da exposição que se segue.

Cabe ressaltar que, sob o ponto de vista conceitual, os documentos arquivísticos eletrônicos têm as mesmas características dos documentos tradicionais.

\section{O que é arquivo}

Ao longo da história, a conceituação de arquivo mudou em conformidade com as mudanças políticas e culturais que as sociedades ocidentais viveram; os arquivos são um reflexo da sociedade que o produz e o modo de interpretálo também acompanha as mudanças que ocorrem. Fatores tais como a finalidade dos arquivos ou os suportes utilizados já foram considerados como definidores do arquivo e, hoje, não o são mais. Menne-Haritz (1994), por exemplo, aponta o surgimento dos documentos eletrônicos como o evento que permitiu ao arquivista entender que o que o motiva a avaliar os documentos ${ }^{3}$ não são problemas de espaço ou custo para o armazenamento, mas, segundo a autora, é a redundância de informações (p. 530).

Assim, não há uma conceituação de arquivo que seja definitiva. Alguns autores, como Rousseau e Couture (1994, p. 284), têm definido arquivo como um conjunto de informaçôes, e não como um conjunto de documentos. Mesmo que não haja dúvidas de que arquivo é um conjunto de informações, entende-se que o termo informação não é esclarecedor quando se deseja conceituar arquivo. Entende-se que a informação arquivística não prescinde do seu suporte, mesmo que ele não seja passível de leitura a olho nu. Dentre outras justificativas para isso, tem-se que a Autenticidade da informação arquivística depende de um conjunto de referências dentre as quais estaria o suporte que contém a informação. 
Elege-se aqui a seguinte definição:

arquivo é um conjunto de documentos produzidos e recebidos no decurso das ações necessárias para o cumprimento da missão predefinida de uma determinada entidade coletiva, pessoa ou familia.

Esquematicamente tem-se:

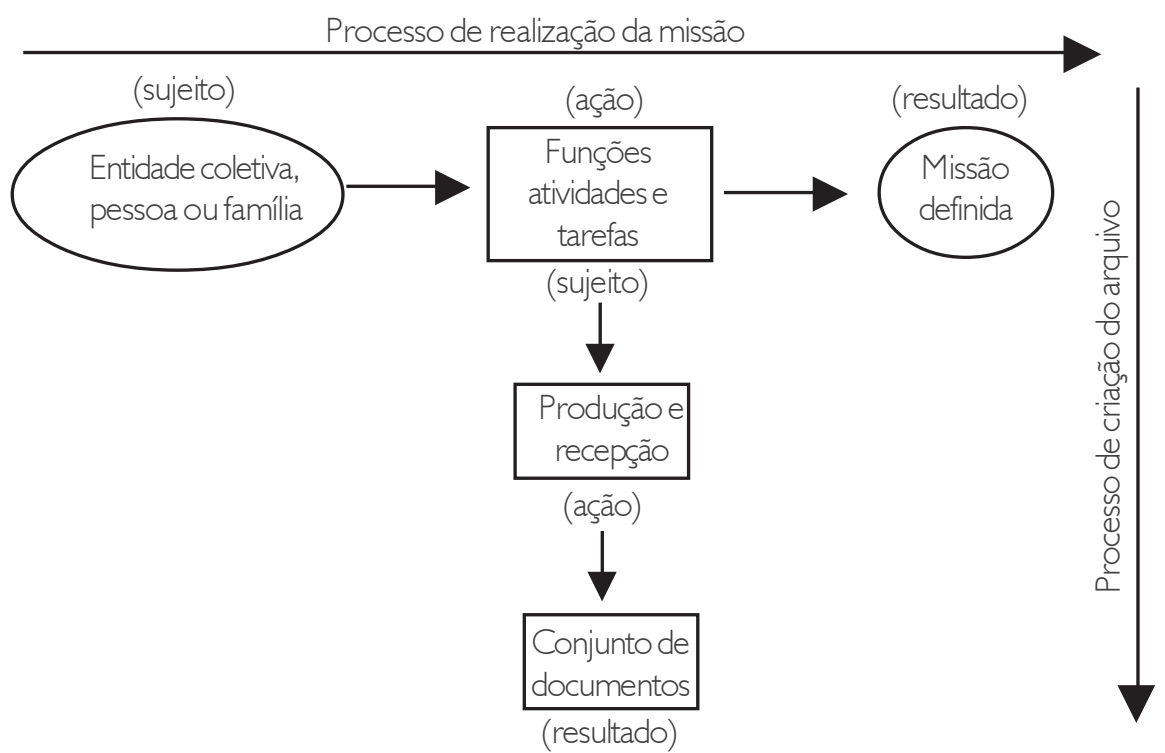

que é ação, no processo de realização da missão, passa a ser o sujeito no processo de criação do arquivo.

$\bigcirc$ arquivo é, então, o resultado de dois processos integrados. processo de produção e recepção de documentos resulta do processo de realização da missão ${ }^{4}$. Na perspectiva jenkisoniana, essa concepção do que é arquivo, ancorada na origem dos documentos, torna-se referência para o tratamento do arquivo em suas três fases.

\section{Os princípios arquivísticos}

A história da teoria dos arquivos começa em I 84 I, meio século após a criação dos Archives Nationales de Paris (Schellenberg, 1973, p. 4), com a publicação de algumas instruções aos arquivistas, onde aparece pela primeira vez o respect des fonds. Em Silva et al. (2002) encontra-se a transcrição de um trecho das instructions pour la mise em ordre et le classement des archives départementales et communales ${ }^{5}$ :

$1{ }^{\circ}$ Rassembler les différents documents par fonds, c'est-à-dire former collection de tous titres qui proviennent d'un corps, d'un établissement, d'une famille ou d'un individu, et disposer d'aprés un certain ordre les différents fonds ; $[\ldots]^{6}$.

E depois :

A l'égard des fonds, il importe de bien comprendre que ce mode de classement consiste à réunir tous les titres qui étaient la propriété d'un même établissement, d'un même corps ou d'une famille, et que les actes qui y ont seulement rapport ne doivent pas être confondus avec le fonds de cet établissement, de ce corps, de cette famille? (p. 107).
${ }^{4}$ A missão da entidade ou pessoa que produz um arquivo seria tanto o resultado das suas atividades quanto o seu objetivo.

5 "Instruções para a ordenação e classificação dos arquivos departamentais e comunais (municipais)."

6 "Re-ajuntar os diversos documentos por fundo, ou seja, formar coleção de todos os títulos que provêm de uma corporação, de uma instituição, de uma família ou de um indivíduo, e dispor, segundo uma certa ordem, os diversos fundos; [...]". (Tradução do autor).

7 "Com relação aos fundos, importa bem compreender que seu modo de classificação consiste em reunir todos os títulos que foram propriedade de uma mesma instituição, de uma mesma corporação ou de uma família, e que os registros que apenas se relacionam a estes não devem ser confundidos com o fundo dessa instituição, dessa corporação, dessa família". (Tradução do autor). 
${ }^{8}$ Esse princípio também se aplica quando se trata de documentação eletrônica. À primeira vista, o nome sugere um pressuposto relativo à ordenação física dos documentos e, inicialmente, o foi. Mas, ao examinar o seu significado, é possível desvinculá-lo do suporte e entender que a ordem original é, antes de tudo, o modo como se estrutura $\circ$ acesso aos documentos.
Até a edição dessas instructions, o arranjo dos fundos de arquivo nos Archives Nationales era estruturado em seções baseadas nos seguintes temas: Seção Legislativa, Seção Administrativa, Seção Histórica, Seção de Propriedade, Seção Judicial (SCHELLENBERG, I973, p. 208). Isso significava mesclar documentações provenientes de órgãos diversos em um mesmo conjunto chamado seção. A introdução da noção de respeito aos fundos se propunha a possibilitar a recuperação das informações originadas de um mesmo produtor de documentos, ou seja, se propunha contextualizar as informações no universo da sua criação.

Duchein (1982, p. I5) utiliza-se da imagem de sítio arqueológico para fazer uma comparação didaticamente interessante para a compreensão da importância do respeito aos fundos. Ele se apóia na evolução sofrida pelo tratamento dos sítios arqueológicos: até uma determinada época, um sítio encontrado era desfeito e suas peças retiradas e levadas para os museus. Era a época dos grandes sistemas de classificação científica. Hoje, procura-se manter o sítio tal qual ele foi encontrado de maneira a ser possível identificar como e porque aquelas peças estão ali. A visualização da noção de sítio arqueológico ajuda a perceber que, ao se retirar peças documentais do seu lugar original, pode-se destruir a informação do significado das peças no seu contexto e, portanto, destruir a possibilidade de plena compreensão dos documentos.

Mas o respeito aos fundos, editado nas instruções francesas, não foi devidamente entendido e cumprido naquele momento. Mais tarde, os alemães definiram dois outros princípios que refletem o respect des fonds. o princípio de proveniência, que costuma ser tratado como sinônimo do princípio de respeito aos fundos, e o de manutenção da ordem original. Mais recentemente é definido como o princípio de integridade ou indivisibilidade.

As bases teóricas para se trabalhar os arquivos têm como eixo os três princípios mencionados cujas definições podem ser consideradas como se segue.

Segundo o Dicionário de Terminologia Arquivística da Associação dos Arquivistas Brasileiros (1996), o princípio de proveniência é o "Princípio segundo o qual os arquivos originários de uma instituição ou de uma pessoa devem manter sua individualidade, não sendo misturados aos de origem diversa" (p. 6I).

Este princípio é o primeiro que define um conjunto de documentos como arquivo. Enquanto os demais conjuntos documentais são coleções de itens selecionados, escolhidos previamente, o conjunto de documentos que forma o arquivo se faz num processo natura/de acumulação, a partir do fluxo da sua produção/recepção por um único sujeito, seja uma entidade coletiva ou uma pessoa. Os documentos são acumulados à medida que são produzidos em decorrência de atividades que são necessárias para a realização da missão do seu produtor.

Quanto ao princípio de manutenção da ordem original ${ }^{8}$, Duranti ( 1 994b) o considera como um princípio de proveniência sob o ponto de vista interno do arquivo (p. 57). A ordem original seria aquela em que os documentos de um mesmo produtor estão agrupados conforme o fluxo das ações que os produziram ou receberam. Se o documento é a corporificação de ações que ocorrem em um fluxo temporal, a ordem original, ou melhor, a ordem dos documentos em correspondência com o fluxo das ações torna-se indispensável para a compreensão dessas ações e, conseqüentemente, para a compreensão do significado do documento. 
Sousa (2003) discute o papel dos princípios de proveniência e de manutenção da ordem original na classificação de arquivos de uso corrente:

Podemos [...] entender os princípios de respeito aos fundos e o da ordem original como princípios de divisão ou de classificação naturais, pois são atributos essenciais e permanentes ao conjunto (arquivo) a ser dividido. [...] a origem [do] conjunto de documentos é sua marca indelével, inseparável, é o que Ihe dá inteligibilidade e identidade. (p.25I).

E mais adiante:

outro princípio que fundamenta as ações de classificação de informações arquivísticas é o princípio da ordem original. Para Rousseau e Couture (1998, p .83), essa vinculação é representada, inclusive, na denominação adotada para os princípios: primeiro grau do princípio da proveniência e segundo grau do princípio da proveniência. Este último visa o respeito ou a reconstituição da ordem interna do fundo. (p. 257).

Sendo assim, o princípio de manutenção ou reconstituição da ordem original está no princípio de proveniência de segundo grau, ou seja, a proveniência do item documental, que é a ação que o gerou, oferecerá sua identidade.

$\bigcirc$ princípio de indivisibilidade ou integridade sempre esteve implícito ao princípio de respeito aos fundos, mas é em uma das publicações recentes da brasileira Heloisa L. Bellotto (2002) que encontramos sua definição moldada: "os fundos de arquivo devem ser preservados sem dispersão, mutilação, alienação, destruição não autorizada ou adição indevida ...". (p. 2l).

Considerando-se o respeito à proveniência do conjunto documental e à ordem original (proveniência de cada documento) como imprescindíveis para o tratamento dos arquivos, fica evidente que a dispersão de documentos pode comprometer a inteligibilidade do arquivo.

\section{As características intrínsecas ao arquivo}

Os princípios arquivísticos estabelecem três características intrínsecas ao arquivo que podem ser assim designadas: a singularidade do produtor do arquivo, a filiação dos documentos às ações que promovem a missão definida? e a dependência dos documentos dos seus pares.

A singularidade do produtor do arquivo dá-se em função do respeito à proveniência. Tem-se que um conjunto de documentos que foram produzidos e recebidos por sujeitos distintos não se constitui em um arquivo. A relação entre o produtor - entidade, pessoa ou família - e o arquivo fornece a identidade do conjunto de documentos e sua singularidade é indispensável.

A singularidade do produtor determina, também, a singularidade do próprio arquivo. Mesmo que hajam duas entidades com a mesma missão e cujas funções atividades tarefas sejam definidas da mesma forma, elas não gerarão arquivos idênticos. O manual publicado pela Associação dos Arquivistas Holandeses fornece um postulado que corrobora essa perspectiva: "Cada arquivo possui, por assim dizer, personalidade própria, individualidade
${ }_{9}^{9}$ Ressalva-se que o próprio resultado da missão muitas vezes torna-se documento do arquivo quando the é dado, pelo produtor, o caráter de amostra ou modelo para futuras ações. Como exemplo, podese citar os livros de uma editora ou os produtos de uma indústria de bens de consumo não perecíveis. A literatura arquivística não discute esses documentos mas os arquivistas, de maneira geral, entendem que a partir do momento que o produtor do arquivo atribui valor de referência a itens que se originaram na realização da sua missão, esses itens tornam-se documentos do seu arquivo. 
peculiar, com a qual é mister se familiarizar o arquivista antes de proceder à sua ordenação"(1960, p. 13).

$\bigcirc$ Conselho Internacional de Arquivos, ao editar a norma para descrição de arquivos - ISAD(G), indica procedimentos baseados nos princípios arquivísticos sem determinar uma estrutura fixa de organização ou estabelecer códigos e títulos. Cada arquivo merecerá sempre uma análise, planejamento e tratamento próprios à sua conformação.

A filiação do documento à ação que o produziu ou recebeu dá-se em função do respeito à manutenção da ordem original ou o respeito à proveniência interna. Tem-se que um documento adquirido ou produzido recebido por motivos alheios às funçôes atividades tarefas do sujeito que o acumula, não se define como documento de arquivo. Essa filiação do documento à atividade que o gerou fornece identidade a ele individualmente e em pequenos grupos. $\bigcirc$ documento corporifica a ação e, portanto, o que o identifica é a ação que o gerou.

A dependência do documento dos demais criados em prol da mesma missão que o gerou baseia-se no princípio de integridade ou indivisibilidade. Tem-se que a realização da missão de uma entidade, pessoa ou família é um processo constituído por diversas ações que geram documentos. Caso se mantivesse apenas um ou outro documento e se eliminassem os demais, esse documento seria apenas um documento que pertenceu ao arquivo daquele produtor, não se poderia considerá-lo o arquivo do seu produtor.

Mas não seria a multiplicidade de documentos o fator determinante para que o arquivo forneça o seu significado. Exemplificando, caso uma entidade iniciasse a realização de uma missão e se interrompesse com a produção/ recepção de apenas um documento, este documento poderia ser dito que o arquivo da entidade encerrou suas atividades. Assim, o que permite que um documento isolado seja considerado um arquivo é o fato de não terem sido eliminadas informações relacionadas a ele contidas em outros documentos, é o fato do arquivo não ter sido mutilado, é o fato de o documento não ter sido separado dos demais originados da realização de uma mesma missão.

Consideram-se essas três características como condição para se definir um conjunto de documentos como arquivo e para definir um documento isoladamente como sendo arquivístico.

\section{As qualidades do arquivo e seus documentos}

As chamadas qualidades do arquivo assumem o papel de orientadoras no tratamento dos arquivos. São qualidades desejadas em um arquivo, mas não determinantes, como o são as três características intrínsecas, para se definir um conjunto de documentos como arquivo. Luciana Duranti (1994b) define cinco qualidades do arquivo ou dos seus documentos. São elas: unicidade, cumulatividade, organicidade, imparcialidade e autenticidade. Verifica-se a seguir, através também de outros autores, como essas qualidades são definidas e sua justificativa.

Unicidade - "não obstante forma, gênero, tipo ou suporte, os documentos de arquivo conservam seu caráter único, em função do contexto em que foram produzidos". (BELLOTTO, 2002, p. 2 I). Ou seja, documentos duplicados não são necessariamente o mesmo. 
A Unicidade refere-se à relação de cada documento com a ação que o gerou. Sua especificidade seria o enfoque em documentos duplicados (cópias) encontrados dentro de um mesmo arquivo, mas em subconjuntos documentais distintos porque produzidos ou recebidos no exercício de ações distintas. Se a filiaçã̃o dos documentos às ações indica que é a ação que dá identidade ao documento, tem-se que o conteúdo do documento não deve ser levado em consideração para a sua identificação dentro de um conjunto documental, e sim o contexto da sua produção.

Cumulatividade $^{10}$ - Bellotto (2002) assim define a Cumulatividade que ela chama de qualidade de Naturalidade na acumulação: "os documentos não são colecionados e sim acumulados, naturalmente, no curso das ações, de maneira contínua e progressiva". (p. 25).

Os itens documentais de um arquivo não são escolhidos previamente para serem acumulados, eles se acumulam à medida que são produzidos. Mas uma boa Cumulatividade, aquela que promove a perfeita organicidade do arquivo, se realiza quando os documentos são organizados de acordo com o desenvolvimento das ações; quando o fluxo de acumulação acompanha o fluxo das ações que criam os documentos. Isso dificilmente se realiza perfeitamente sem que haja uma ação orientada para esse fim. $\bigcirc$ que orientará essa ação será o chamado Plano de Classificação que se constitui na principal atividade da gestão de documentos de uso corrente.

Organicidade - Se um arquivo é formado por um conjunto de documentos que se originam de ações articuladas em prol da missão de uma entidade, tem-se que ele resulta em um todo orgânico cujas partes são interrelacionadas de modo a fornecer o sentido do conjunto.

A Organicidade do arquivo realiza-se através da acumulação dos documentos. Um arquivo sempre tem alguma Organicidade, as próprias atividades acabam por impor alguma ordem aos documentos gerados. Mas a acumulação com base em um Plano de Classificação, de modo correspondente ao fluxo do desenvolvimento das ações, de modo que as inter-relações existentes entre as funções atividades tarefas reflitam-se nos documentos, essa acumulação faz com que o arquivo reflita, no seu todo, a missão realizada.

Imparcialidade - Jenkinson foi quem a definiu. Sua perspectiva é dos arquivos produzidos por entidades da administração pública ou privada o conceito de Imparcialidade sugere que o documento nasce por uma imposição da natureza das atividades de uma instituição, e não porque houve uma escolha de ter-se um documento para essa ou aquela finalidade. A imparcialidade dos documentos refere-se à capacidade dos documentos de refletirem fielmente as ações do seu produtor. $\bigcirc$ autor enfatiza a verdade administrativa do documento e não a verdade do seu conteúdo. $\bigcirc$ motivo da criação de um documento, independentemente do seu conteúdo ser ou não, suponhamos, uma fraude, seria legítimo no que se refere à sua relação com as atividades da entidade que o criou.

Conclui-se que a Imparcialidade dos documentos está intrinsecamente relacionada à Organicidade do arquivo. A boa Oganicidade promove os seus subconjuntos de documentos a espelhos fieis às atividades e promove, o arquivo como um todo, a espelho da missão realizada pelo produtor do arquivo.

Autenticidade - Num primeiro momento, o termo Autenticidade leva a pensar que ele refere-se à veracidade do conteúdo de um documento de arquivo como prova perante a lei. Contudo, ao analisar melhor esse conceito, entende-se que se trata, antes de tudo, de uma questão arquivística, pois nela
10 É necessária uma transposição desse conceito para os documentos eletrônicos pois sua acumulação se traduz na forma estabelecida de acesso ao documento e não na ordenação física dos documentos. 
está implícita a manutenção da integridade do fundo de arquivo.

Jenkinson foi quem formulou a proposição da Autenticidade também na perspectiva das administrações públicas e privadas e tendo em vista, como todo arquivista do seu tempo, os arquivos de guarda permanente.

Desde que se entenda que a Imparcialidade diz respeito à verdade administrativa dos documentos, ou seja, ao fato de os documentos constituírem-se num reflexo fiel das atividades desenvolvidas, vê-se que a Autenticidade depende da manutenção dessa Imparcialidade. Jenkinson identifica a possibilidade dessa garantia no continuum da criação, manutenção e guarda pelo seu produtor.

Já em meados do século passado, Schellenberg afirma que não é possível manter a custódia ininterrupta dos arquivos modernos. Contudo, importa entender que os arquivos estão sujeitos a perder sua Organicidade, Imparcialidade e Autenticidade se tratados e preservados de maneira pouco rigorosa.

Camargo (2003) assim aponta o perigo da perda das inter-relações dos documentos:

Se os documentos de arquivo são desprovidos de autonomia, isto é, retiram sua autenticidade das relações que mantêm com as demais unidades que integram o conjunto, dentro do princípio de consignação que o rege, qualquer intervenção no sentido de romper seu equilíbrio originário acaba por 'implodir' o próprio arquivo.

A falta de autonomia do documento, a qual a autora se refere, diz respeito à dependência do documento de arquivo dos demais que estão relacionados a ele e da sua filiação às atividades que o gerou. Cada documento encontrará seu significado dentro do conjunto ao qual pertence desde que mantida a Organicidade do arquivo.

\section{A gestão de documentos arquivísticos}

Na perspectiva da arquivologia, gestão de documentos é " um conjunto de medidas e rotinas visando à racionalização e eficiência na criação, tramitação, classificação, uso primário e avaliação de arquivos" (DICIONÁRIO de terminologia arquivística, 1996).

Sousa (2003, p. 240) entende a classificação como a medida crucial dentro da gestão dos arquivos. A classificação do documentos determina e é determinada pelas demais atividades que compõem a Gestão de Documentos. Convencionou-se, entre os autores da arquivologia, que a classificação dos documentos de caráter permanente denomina-se Arranjo. Quando se o utiliza o termo classificação, ele se refere aos arquivos correntes.

Seguindo esta orientação, para melhor delimitar a discussão que se segue, discutir-se-á a gestão de documentos arquivísticos com enfoque na sua classificação. Segundo o Dicionário... (1996), classificação é a "Seqüência de operaçôes que, de acordo com as diferentes estruturas, funçôes e atividades da entidade produtora, visam distribuir os documentos de um arquivo" (p. I 6).

Schellenberg, em 1956, definiu os três elementos da classificação dos documentos públicos. "a) a ação a que os documentos se referem; b) a estrutura 
do órgão que os produz; e c) o assunto dos documentos"(2004, p. 84).

O autor explica cada uma delas: "Uma ação pode ser tratada em termos de funções, atividades e atos (transactions)"(p. 84). E "O segundo elemento a ser observado na classificação de documentos é a organização da entidade criadora. [...] A estrutura que se imprime a um órgão [...]"(p. 86).

Schellenberg trata separadamente da classificação por assunto pois ela refere-se a documentos não arquivísticos identificáveis dentro de arquivos de órgãos públicos. Considera-se que as recomendações do autor podem ser aplicadas também aos arquivos de entidades privadas ou de uma pessoa:

Conquanto os documentos públicos, geralmente, devam ser agrupados segundo a organização e função, far-se-á exceção a essa regra para certos tipos de documentos, tais como os que não provêm da ação governamental positiva ou não estão a ela vinculados. Incluem-se nesses documentos as pastas de referência e informações. [...] só em casos excepcionais os documentos públicos devem ser classificados em relação aos assuntos que se originam da análise de determinado campo de conhecimento. Esses casos excepcionais referem-se a materiais de pesquisa, de referência e similares. (p. 92).

A interpretação de que o significado do documento se encontra no contexto da sua criação é reforçado por A. C. Rodrigues (2005), ao discutir o tratamento de documentos arquivísticos:

[...] Os arquivos conservam registros de ações e de fatos como prova da gestão que os produziu, dos quais são produtos naturais. [...] o arquivo se forma por um processo de acumulação natural, o que significa dizer que tem o atributo especial de ser um conjunto orgânico e estruturado, onde seu conteúdo e significado só podem ser compreendidos na medida em que se possa ligar o documento ao seu contexto mais amplo de produção, às origens funcionais (p. 5).

Sousa (2003) aponta muitos problemas nos arquivos correntes da administração pública brasileira derivados da falta de uma metodologia bem delineada para a classificação. Citam-se alguns trechos do seu trabalho, buscando identificar os princípios arquivísticos que estão implícitos às observações do autor:

Os arquivos montados nos setores de trabalho são acervos arquivísticos constituídos de documentos ativos, semi-ativos e inativos, misturados a outros passíveis de eliminação e a documentos não orgânicos, que não são considerados de arquivo e que são produzidos ou recebidos fora do quadro das missões de uma organização (p. 258).

A referência inicial à ausência de transferência e recolhimento de documentos é relacionada ao conceito de ciclo de vida dos documentos que, na verdade, não encontra respaldo nos princípios arquivísticos apesar de ser amplamente aceito pelos autores de manuais de tratamento de arquivo. Em seguida, o autor faz referência à presença de documentos não orgânicos misturados aos demais. Esta situação contraria o próprio conceito de arquivo e o princípio de manutenção da ordem original ou de procedência interna. Ou 
' Espécie documental: Configuração que assume um documento de acordo com a disposição e a natureza das informações ( I) nele contidas. (DICIONÁRIO de terminologia arquivística, p. 34). seja, o documento que não resultou de atividades que compõem a missão do seu produtor não tem relação orgânica com os demais e, portanto, não é um documento arquivístico. Ele não possui a característica de filiação às ações.

E mais adiante:

A organização, quando existe, fundamenta-se no empirismo e na improvisação. Os métodos oscilam entre a fragmentação dos dossiês de assunto, o arquivamento por espécie documental"', por ato de recebimento e expedição, pela numeração etc. [...] Há casos em que esse trabalho é feito por bibliotecários. Eles criam códigos de classificação baseados na lógica e na metodologia da sua profissão. Em geral dispõem os documentos por assuntos ou pelo nome pelos quais são conhecidos e aplicam a codificação decimal extraída do método de Mevil Dewey. Uma das principais características desses instrumentos é a fragmentação das unidades documentais. Dessa forma, tratam os documentos individualmente, como se fossem livros ou periódicos. (p. 259).

O autor identifica a implosão do arquivo, como diz Camargo citada nas linhas anteriores. A Organicidade é perdida com a fragmentação das unidades documentais. Identifica-se neste relato o desrespeito ao princípio de integridade e também à qualidade de cumulatividade, pois a organização por espécie documental ou por ato de recebimento e expedição, fatalmente, tira os documentos da sua ordem natural. Perdese a referência que explicita a inter-relação dos documentos, descontextualiza-se o documento ignorando-se a sua dependência dos demais para oferecer significado.

Sousa prossegue:

Nos últimos anos, com o avanço e a banalização da microinformática, tem aumentado sensivelmente o número de documentos em suportes informáticos. [...] Normalmente, eles não são considerados documentos de arquivo, apesar de terem sido produzidos ou recebidos no quadro das funções e das atividades dos órgãos. Permanecem, geralmente, nos setores que os acumularam. Em alguns casos, recebem a denominação de técnicos e são enviados a bibliotecas e a centros de documentação (p. 26 |-262).

Vê-se aqui também a não observância dos princípios de proveniência interna e de integridade ou indivisibilidade. Mesmo que o armazenamento físico de alguns documentos seja feito em local separado, por exemplo, por questões de conservação, a dependência desses documentos dos demais que foram produzidos e recebidos no curso das atividades em prol da missão deverá ficar explicitada em um instrumento de pesquisa de modo a não se perder a organicidade do arquivo. Quando se retiram documentos do conjunto ao qual eles pertencem, altera-se o significado desses documentos e dos demais produzidos conjuntamente a eles.

E ainda:

[...] A disposição da documentação existente nos setores de trabalho dos órgãos é invariavelmente abandonada nesses 
depósitos de massas documentais acumuladas. [...] As soluções encontradas resumem-se, em muitos casos, na microfilmagem sem critérios predefinidos. Transfere-se para outros suportes a desorganização existente nos suportes originais. Observa-se, hoje, a substituição desse processo pelo de digitalização (p. 264).

Essa questão aponta para um equívoco freqüente: providenciar meios de preservar a documentação supondo que o problema arquivístico seja assim resolvido. Documentos cujas informações contidas e relacionadas a eles não estão representadas em um instrumento de pesquisa podem ser considerados inexistentes, pois não é possível examinar item por item.

Vê-se que muitos problemas podem ser evitados caso os princípios arquivísticos sejam observados na organização dos arquivos. Apresentase como urgente definir claramente uma metodologia consistente que possa organizar qualquer arquivo corrente, independentemente das peculiaridades de cada um, seja ele público ou privado.

Ao lado da demanda por uma metodologia mais consistente para a gestão de documentos em entidades coletivas, os teóricos da arquivologia são solicitados a repensar seus desenvolvimentos de modo a dar respostas às questões que surgem com o advento da chamada era da informação.

Acredita-se que a partir da definição de arquivo pode-se chegar à definição de informação arquivística: informação arquivística é aquela passivel de ser extraída de um conjunto de documentos desde que estes tenham sido produzidos ou recebidos no decurso das açóes necessárias para a realização da missão predefinida de uma determinada entidade coletiva, pessoa ou familia.

Sendo assim, identificam-se dois níveis de informação no arquivo que, conforme Jardim e Fonseca (1998) afirmam, seriam:

- a informação contida no documento de arquivo, isoladamente;

- $\quad$ e a informação contida no arquivo em si, naquilo que o conjunto, em sua forma, em sua estrutura, revela sobre a instituiç̧ão ou sobre a pessoa que o criou (p. 37I).

Reconhecer dois níveis de informação arquivística significa que, para a elaboração de um Plano de Classificação de documentos, é necessário priorizar uma delas: ou o conteúdo ou a proveniência dos documentos. Respeitando-se os princípios arquivísticos, a viabilização do acesso às informações contidas nos documentos arquivísticos não deverá prejudicar o acesso à informação sobre a origem do documento.

A partir de Schellenberg, os manuais têm orientado a organização dos documentos de uso corrente em uma estrutura que espelhe o desenvolvimento das funções, atividades e tarefas que geram documentos. Em entidades coletivas, identifica-se, de maneira geral, uma série de funções que são realizadas através de certo número de atividades as quais se concretizam na execução de um conjunto de tarefas. Sendo assim, o plano de classificação dos documentos é estruturado em uma cadeia hierárquica de modo que os níveis superiores reflitam as funções 
12 Tipo documental: Configuração que assume uma espécie documental, de acordo com a atividade que a gerou. (DICIONÁRIO de tipologia arquivística, p. 74). desenvolvidas para o cumprimento da missão da entidade; os segundos níveis, as atividades necessárias para a realização de cada função do primeiro nível; e os terceiros níveis, as tarefas relativas a cada uma das atividades. Dentro destes terceiros níveis são ordenados os documentos sob o critério mais adequado àquele tipo ${ }^{12}$ de documento. Essa classificação é chamada funcional.

E a orientação para a organização com vistas ao acesso aos documentos de guarda permanente é estruturada também em uma cadeia hierárquica cujo primeiro nível identifica o produtor do arquivo; o nível ou níveis seguintes correspondem à estrutura organizacional, quando ela existe; e os níveis subseqüentes reproduzem a classificação recebida na fase de uso corrente. Essa organização recebe o nome de Arranjo e sua classificação é chamada organizacional/funcional.

Rodrigues, baseando-se na proposta de Luciana Duranti, tende a considerar como mais adequado partir-se da identificação das tipologias documentais para se proceder a classificação. Diz a autora:

A correta delimitação da tipologia documental, considerada em função do seu contexto de produção, é de fundamental importância para definir sua classificação, valor para preservação ou eliminação e utilização.

Na perspectiva tradicional da arquivística, para o conhecimento da gênese do documento, devemos partir da análise do geral para o particular, do órgão para o resíduo material do exercício de suas competências, que é o documento que circula e é acumulado no arquivo. Este é um axioma arquivístico para um segmento de teóricos na área, mas que vem se tornando objeto de reflexão entre os profissionais que estudam as questões de naturezas teóricas metodológicas propostas pela diplomática contemporânea, também chamada de tipologia documental. (2002, p. 47).

Essa metodologia parte do exame de cada documento ou conjunto de documentos já produzidos para, então, examinar-lhe a gênese. Aponta-se como possível conseqüência da aplicação dessa metodologia, o risco da não observância da qualidade de Unicidade dos documentos. Uma cópia de um documento produzido por um certo departamento de uma entidade que seja recebida por um outro departamento, pode assumir novo significado e receber uma classificação diferente do documento original.

Proceder ao exame das funções, atividades e tarefas para elaborarse a classificação dos documentos por elas produzidos, pode ser a postura mais segura para garantir a representação de todas as ações do produtor dos documentos.

Nos arquivos de guarda permanente, nas instituições arquivísticas públicas, a demanda por conteúdos de documentos descontextualizados, ou seja, por informações contidas em documentos independentemente da ação que os gerou, é comum e freqüente. A prática tem sido, por exemplo, no Arquivo Público da Cidade de Belo Horizonte, uma seleção baseada no Arranjo organizacional, feita com o auxílio do atendente da sala de consultas, e a busca pela informação, documento a documento. 
Promover o fácil acesso aos conteúdos descontextualizados tem se mostrado como uma meta inatingível. Os manuais para organização de arquivos tratam dos índices, por exemplo, como um recurso para o acesso aos conteúdos dos documentos. Contudo, o volume documental dos arquivos permanentes é sempre de dimensões gigantescas. Promover o seu acesso através do Arranjo, que é a prioridade, é tarefa que tem demandado muito tempo e recursos humanos, pois, normalmente, a documentação que é recolhida às instituições arquivísticas não recebeu, na origem, uma classificação funcional.

Nos arquivos de uso corrente, de uma maneira geral, os documentos são buscados pelo seu caráter de evidência dos atos. Podese dizer que apenas potencialmente há demanda por conteúdos descontextualizados. Isso não significa que a busca por recursos que promovam o acesso a informações descontextualizadas seja uma preocupação menor entre os arquivistas.

Vê-se o diálogo com a ciência da informação como o caminho para a arquivologia desenvolver estes recursos. Fonseca (2005) se manifesta em relação a essa questão:

A falta de percepção das relações interdisciplinares entre essas duas áreas do conhecimento é instigante, na medida em que tais relações parecem bastante óbvias, quando se identifica a informação como elemento central do conjunto de objetos de que ambas se ocupam. (p.10).

Buscando-se entender essa dificuldade, aponta-se, inicialmente, que cada uma delas tem questões próprias, de fundo, a serem resolvidas. Por exemplo, o seu objeto. Mas isso não tem impedido que elas se desenvolvam enquanto áreas de conhecimento. Vale, então, verificar a principal diferença de enfoque para a gestão. Tal como foi exposto, a arquivologia parte do motivo da criação do documento para elaborar os instrumentos de acesso à informação. Já para ciência da informação, como se encontra em Marchiori (2002), o ponto de partida para a gestão da informação é a demanda (p. 75). Avaliar como essas duas perspectivas podem se integrar parece crucial para se promover a cooperação desejada.

Dentro do exposto, identifica-se que a arquivologia tem recursos teóricos que podem servir de base para a elaboração de uma metodologia de classificação de documentos arquivísticos que possibilite o fácil acesso à informação arquivística contida no arquivo em si, naquilo que o conjunto, em sua forma, em sua estrutura, revela sobre a instituição ou sobre a pessoa que o criou. Essa classificação permite também o acesso à informação contida no documento a partir de uma seleção com base no contexto de produção do arquivo.

Por outro lado, os princípios, características e qualidades dos arquivos não se prestam como base para a construção de um sistema de pesquisa que permita a seleção de documentos por conteúdos descontextualizados, embora esses construtos devam ser neste caso considerados, a fim de que os sistemas de pesquisa por conteúdos não promovam a perda da referência à origem dos documentos. 


\section{Archival theory and records management}

The purpose of this paper is to present the main concepts of archival science in order to discuss how these concepts can help build a methodology for documents management, as well as identify the main problems to be overcome in accessing archival information.

Key-words: Archives; Achival science; Records management; Information.

\section{REEFRÊECLIAS}

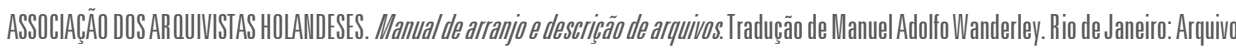
Nacional. 1960.

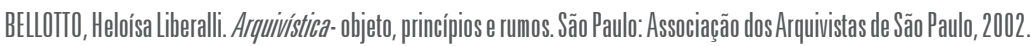

CAMARGO, Ana Maria de A. Sobre o valor histórico dos documentos. Revista do Arguivo de Rio Claro. Rio Claro (SP): n.1, 2003.

COOK, Terry. What is past is prologue: a history of archival ideas since 1898, and the future paradign shift. Archivaralia, Canadà: Association of Canadian Archivists, 43, Spring, 1997.

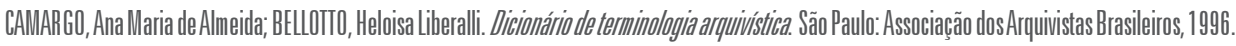

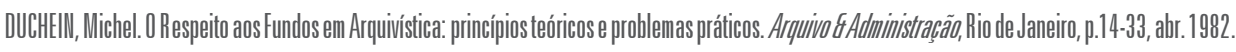
DURAAIII, Luciana. The concept of appraisal and archival theory. Americian Archivist. V. .57,Spingy, 1994a.

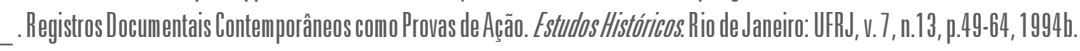

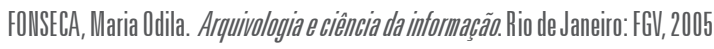

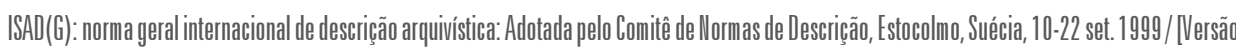
brasileira preparada por Grupo de Irabalho do Arquivo llacional]. Madrid: Subdirección General de los Archivos Estatales, 2000.

JARDIM, José Mlaria. O conceito e a prática de gestão de documentos. Acervo, v. 2, n.2, jul./dez, 1987.

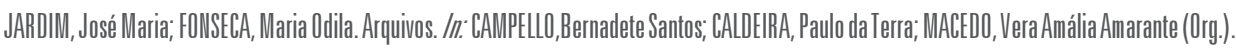

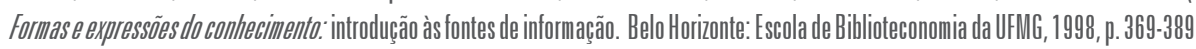

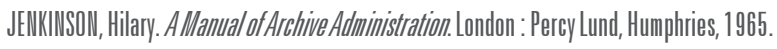

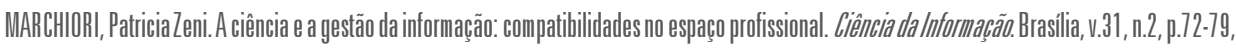
maio/ago. 2002.

MEEWWE-HARIIZ, Angelika. Appraisal or Documentation: Can We Appraise Archives by Select Content? AmericannArchivist, v. 57 , Summer 1994.

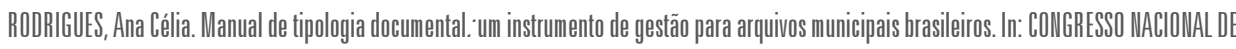
ARQUIVOLOGIA, 1.,2005. Anals... Braślia, 2005.

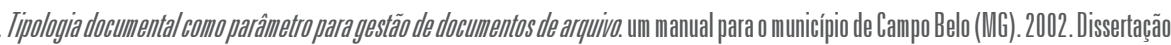

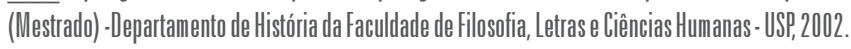

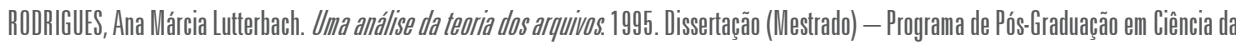
Informaçãa - UFMG, 1995.

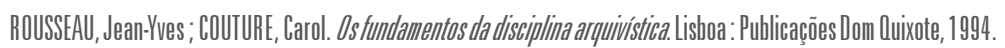


SCHELLENBERG, Theodore Roosevelt. Arguivos modernos. principios e técnicas. 2.ed. Rio de Janeiro: FGV, 1973.

SILVA, Armando Malheiro da; RIBEIRO, Fernanda; RAMOS, vúlio; REAL, Manuel Luís. Arguiviśstica-Teoria e prática de uma ciência da informação. Porto: Afrontamento, 2002.

SOUSA, Renato Tarcísio Barbosa. Os princípios arquivísticos e o conceito de classificação. In: RODRIGUES, Georgete M.; LOPES, lza L. (Org.). Organizzação e Representaçãa do Conhecimento. Brasilia: Thesaurus, 2003. p.240-271.

ISCHAll, Reto. A comparison of Jenkinson and Schellenberg on appraisal. The American Archivist, v. 65, p. 176-195, Fall/Winter, 2002. 